\title{
The Cure is in the Roots: Turmeric
}

\section{Krupa Vyas*}

Berkeley College, Woodbridge, NJ 07095, USA

\begin{abstract}
This study aims to assess the core health benefits of Turmeric. According to most research, Turmeric is proclaimed as the most effective nutritional constituent in existence based on its unparalleled benefits for body and brain. The science supports this herb validating the compounds with medicinal properties.
\end{abstract}

Keywords: Natural healing; Herbs; Ayurveda; Turmeric; Disease prevention; Longevity; New studies and research

Turmeric. Sound familiar? If you belong to an Asian background or work in the field of medicine/ayurveda, it is more likely that you have not only heard of this mystical substance but have also had the opportunity to work with this magnificent ingredient. As an Asian, a person is introduced to this phenomenon in many ways (Figure 1). For example, when a woman learns about her pregnancy, she intakes turmeric to ensure the good health of her and her unborn baby [1]. Traditionally, it is said that taking turmeric when pregnant will ensure the ease in the pain of childbirth as it is analgesic (pain reliever) [1].

So what exactly is turmeric? And why are Asians so crazy about it? To many individuals, the term Turmeric is alien. I was recently speaking to a very good friend of mine and as soon as I mentioned the word Turmeric, he seemed completely baffled as if I was speaking a foreign language to him. Right then, I thought to myself that there are probably hundreds of people just like him who have never even heard of this invaluable resource and are unaware of its natural healing powers.

The Latin name for turmeric is "Curcuma Longa" (scientific name), which comes from the Arabic name for the plant, "Kurkum." and in Sanskrit is called "Haridra" (The Yellow One), "Gauri" (The One Whose Face is Light and Shining), "Kanchani" (Golden Goddess), and "Aushadhi" (Herb). It is called "Jiang Huang" in Chinese, and "Haldi" (Yellow) in Hindi. It is sometimes also referred as "Indian Saffron" $[1,2]$.

Turmeric is certainly no magic but it is indeed magical. It is an age old and well used spice. A relative of ginger, turmeric comes from the root of the Curcuma Longa, a rhizomatous herbacceous perennial plant that grows 5 to 6 feet high in the tropical regions of Southern Asia (India, Indonesia, China, the Philippines, Taiwan, Haiti, Jamaica, Sri Lanka, Indochina and Peru) $[1,3]$. Its roots are bulbs that produce rhizomes, which then produce stems and roots for new plants. It has tough brown skin and deep orange flesh. The roots, or rhizomes and bulbs, are generally boiled and then dried, turning into the familiar yellow powder [3].

The most important chemical components of turmeric are a group of compounds called curcuminoids, which include curcumin (diferuloylmethane), demethoxycurcumin, and bisdemethoxycurcumin. The best-studied compound is curcumin, which constitutes approximately $3.14 \%$ of the powdered turmeric. Turmeric contains health benefiting essential oils such as termerone, curlone, curumene, cineole, and p-cymene. Some general constituents are sugars, proteins, and resins [4].

Turmeric has a peppery, warm and bitter flavor and a mild fragrance slightly reminiscent of orange and ginger, and is sometimes used as an agent to impart a rich, custard-like yellow color [5]. It is used in canned beverages, baked products, dairy products, ice cream, yogurt, yellow cakes, orange juice, biscuits, popcorn color, cereals, sauces, gelatins, etc. Turmeric leaves are used to wrap and cook food and are mainly used in areas where turmeric is grown locally, since the leaves used are freshly picked. Turmeric leaves impart a distinctive flavor [13].

Turmeric is available in many forms like edible spice, fluid extract, tincture and pharmaceutical products such as capsules containing powder [3].

\section{Health Benefits}

Now that we have a clear definition of what turmeric is and how it can be used, it is time to examine the core health benefits. According to most research, turmeric may be one of the most effective nutritional constituent in existence solely based on its unparalleled benefits for body and brain as it treats a myriad of diseases and ailments. Recently, this subject has received abundance of press ever since science has started to back it up validating the compounds with medicinal properties.

"Turmeric is one of the greatest, beneficial medicinal plants in the entire world and It's also one of the most researched medicinal plants

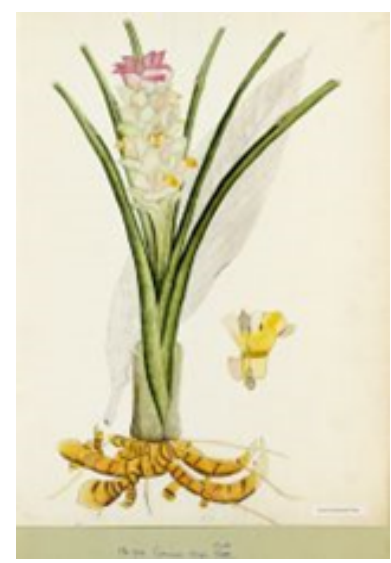

Figure 1: Plant of turmeric.

*Corresponding author: Krupa Vyas, Berkeley College, Woodbridge, NJ 07095 USA, E-mail: krupavyaspro@gmail.com

Received April 17, 2015; Accepted May 29, 2015; Published June 03, 2015

Citation: Vyas K (2015) The Cure is in the Roots: Turmeric. J Nutr Disorders Ther 5: 163. doi:10.4172/2161-0509.1000163

Copyright: @ 2015 Vyas K. This is an open-access article distributed under the terms of the Creative Commons Attribution License, which permits unrestricted use, distribution, and reproduction in any medium, provided the original author and source are credited. 
in history." said ethnobotonist, author and "Medicine Hunter" Chris Kilham. In addition, one of the most comprehensive summaries of turmeric studies to date was published by the ethnobotanist James A. Duke, Phd., in the October, 2007 issue of Alternative \& Complementary Therapies, and summarized in the July, 2008, issue of the American Botanical Council publication HerbClip [6]. Upon reviewing about 700 studies, James A. Duke concluded that turmeric appears to outperform many pharmaceuticals in its effects against several chronic, debilitating diseases [6]. As of January 2015, there are nearly 5,000 studies and articles on curcumin or turmeric listed in the National Institutes of Health PubMed database, one of the top directories for medical research.

Curcumin is a bioactive substance of turmeric. Curcumin fights inflammation at the molecular level and is the main active ingredient posing as a very strong anti-bacterial, anti-septic, anti-spasmodic, antifungal, anti-inflammatory, anti-allergic, anti-oxidant, anti-mutagenic, anti-carcinogenic, astringent, carminative, cholagogue, digestive, diuretic, stimulant, and vulnerary $[1,3,4,8]$. There are at least 20 molecules that are anti-biotic, 14 that are known cancer preventatives, 12 that are anti-tumor, 12 are anti-inflammatory and at least 10 different anti-oxidants [1]. Anti-oxidants scavenge molecules in the body known as free radicals which damage cell membranes, tamper with DNA, and even cause cell death [3]. Anti-oxidants fight free radicals and may reduce or even help prevent some of the damage caused by free radicals [3]. Curcumin neutralizes free radicals by stimulating the body to produce its own anti-oxidant enzymes [7]. Inflammation is crucial as it helps the body fight foreign invaders and repair damage. Curcumin blocks Nuclear Factor Kappa Beta (NF-kB), a molecule that travels into the nuclei of cells and turns on genes related to inflammation [7]. NF-kB is believed to play a major role in many chronic diseases [7]. Curcumim boosts brain-derived neurotrophic factor, linked to improve brain function. One of the main drivers of this process is Brain-Derived Neurotrophic Factor (BDNF), which is a type of growth hormone that functions in the brain [7]. Interestingly, curcumin can increase brain levels of BDNF and may be effective at delaying or even reversing many brain diseases and age-related decreases in brain function [7]. Depression, a very common brain disease linked to the reduced levels of BDNF and a shrinking hippocampus, a brain area responsible for learning and memory, has been defeated by the ever promising curcumin by proving that curcumin is as effective as an antidepressant $[5,4]$.

Peer-reviewed research has found that turmeric can positively impact over 581 diseases and curcumin alone has been found to affect over 560 diseases [9]. In a study published in the July edition of the Journal of Nutritional Biochemistry, researchers and scientists have discovered that curcumin reduced brain tumors in 9 out of the 11 studies by $81 \%$ without evidence of toxicity [9]. There are few human studies examining curcumin as an agent to ameliorate neurological disorders. An epidemiological study of elderly Singaporeans who ate curry with turmeric had better cognitive function than those not consuming curry.

One of the most important properties of curcumin is boosting immunity. As Dr. Joseph Mercola said " 5 to 8 times stronger than vitamin $\mathrm{E}$ and stronger than vitamin $\mathrm{C}$, this anti-oxidant breakthrough may help boost your immunity, maintain normal cholesterol levels, and put the brakes on aging" [10]. His claims are well substantiated by the various studies. For example, Jagetia and Aggarwal at the Department of Experimental Therapeutics, The University of Texas M. D. Anderson Cancer Center, Houston, and USA reported that "Interestingly, curcumin at low doses can also enhance antibody responses [10]. This suggests that curcumin's reported beneficial effects in arthritis, allergy, asthma, atherosclerosis, heart disease, Alzheimer's disease, diabetes, and cancer might be due in part to its ability to modulate the immune system" [10]. Curcumin down-regulates certain inflammatory transcription factors such as NF-kB, enzymes such as cyclooxygenase 2 and 5 lipoxygenase, and cytokines such as tumor necrosis factor (TNF), interleukin-1 (IL-1) and interleukin 6 (IL-6) and hinders the development of these diseases [10].

Curcumin prevents the development of type 2 diabetes in people who have prediabetes. This has been shown in a Thai study published in the journal Diabetes Care where the researchers found that people with prediabetes who took capsules containing curcumin were less likely to develop type 2 diabetes compared with people who did not take the curcumin capsules [10]. The reason, says Drew Tortoriello, an endocrinologist and research scientist at Naomi Berrie Diabetes Center at Columbia University Medical Center, is that turmeric lessens insulin resistance and prevents type 2 diabetes [10].

Curcumin helps promote weight loss and reduce the incidence of obesity-related diseases. The inflammation associated with obesity is due in part to the presence of immune cells called macrophages in fat tissues throughout the body [10]. These cells produce cytokines that can cause inflammation in organs such as the heart, and islets of the pancreas, while also increasing insulin resistance in muscle and liver [10]. Scientists believe that turmeric suppresses the number and activity of these cells and help reduce some of the adverse consequences of obesity [10].

When it comes to heart disease, curcumin is known to improve the function of the endothelium, which is the lining of the blood vessels $[3,7]$. It is well known that endothelial dysfunction is a major driver of heart disease and involves an inability of the endothelium to regulate blood pressure, blood clotting and various other factors [3,7]. There is considerable preclinical evidence indicating that curcumin exhibits a variety of cardio-protective properties [11]. First of all, curcumin may protect against cardiac injury, in large part because of its antiinflammatory actions [11]. Several animal studies have suggested that curcumin administration [eg, $70-100 \mu \mathrm{mol} / \mathrm{kg}$, intravenously] protects the heart from damage following cardiac ischemia and reperfusion $[\mathrm{I} / \mathrm{R}]$ and from cardiopulmonary bypass (CPB) [11]. Curcumin acted in part to protect the myocardium against ischemic damage by suppressing pathways generating reactive oxygen species and lipid peroxidation and by up-regulating other pathways that detoxify free radicals [11]. I/R and CPB were ameliorated by curcumin's ability to counteract the up-regulation of cardiac pro-inflammatory genes and to suppress the production of pro-inflammatory cytokines following damage to the heart [11]. In mice, curcumin dosing (50-100 mg/kg per day, subcutaneously, for 1-2 week) prevented experimentally induced cardiac hypertrophy, fibrosis, inflammation, and heart failure in part via its inhibition of p300 histone acetyltransferase [11]. Curcumin also inhibited chemically induced cardiac injury following administration of such agents as isoproterenol and adriamycin [11]. Curcumin may be cardio-protective by suppressing atherosclerotic lesion development [11]. It can act in a variety of ways including inhibiting low-density lipoprotein oxidation, suppressing proliferation of vascular smooth muscle cells, decreasing thrombosis, reducing aortic fatty streak formation, and blocking homocysteine-induced endothelial dysfunction [11]. Provision of curcuminoids $(30-90 \mathrm{mg} / \mathrm{kg}$ per day, e.g., for 12 week) also has a lipid-lowering effect in rats fed high-fat diet [11]. There is some speculation that curcumin's anti-inflammatory 
actions may help in the prevention of atrial and ventricular arrythrmias [11]. Recent preliminary evidence suggests that curcumin has the potential to prevent stroke and lessen vascular inflammation and cerebral vasospasm following hemorrhagic stroke [11].

Researchers have been studying curcumin as a beneficial herb in cancer treatment $[5,6,7]$. It can affect cancer growth, development and spread at the molecular level [3,7]. In the laboratory, the anti-oxidants in turmeric kill cultures of cancer cells from the skin, bloodstream, and ovaries [12]. Studies have shown that it can reduce angiogenesis (growth of new blood vessels in tumors), metastasis (spread of cancer), as well as contributing to the death of cancerous cells [7]. However, there is some evidence that it may help prevent cancer from occurring in the first place, especially cancers of the digestive system [7]. Turmeric and curcumin has been proven to be powerful suppressors of cancer growth and spread [9]. In fact, researchers at University of California, Los Angeles (UCLA) found that curcumin is capable of blocking enzymes necessary for cancer to grow [9]. Involving 21 participants, each took 1,000 milligrams of chewable curcumin tablets [9]. Upon completion of the experiment, the results were evaluated by an independent lab in Maryland and the lab test verified that the supplementation did indeed inhibit spread of the malignant cells, and therefore blocked cancer growth [9]. Dr. Bharat Aggarwal, who conducts cancer research at the Jawaharlal Nehru Centre for Advanced Scientific Research in Bangalore, India stated that "We have not found a single cancer on which curcumin does not work" [1]. Ayurveda especially recommends turmeric for cancers of the female reproductive system, specifically breast and uterine cancer, and to treat benign tumors as well [1]. James A. Duke, Phd., found more than 200 citations for turmeric and cancer and more than 700 citations for curcumin and cancer [6]. He noted that in the handbook Phytochemicals: Mechanisms of Action, curcumin and/or turmeric were effective in animal models in prevention and/ or treatment of colon cancer, mammary cancer, prostate cancer, murine hepatocarcinogenesis (liver cancer in rats), esophageal cancer, and oral cancer [6]. James A. Duke said that the effectiveness of the herb against these cancers compared favorably with that reported for pharmaceuticals [6]. Researchers from Cancer Biology Research Center, South Dakota, claim that curcumin may be an effective chemopreventive and therapeutic agent for cervical cancer prevention and treatment [10]. Researchers found that curcumin treatment suppresses cervical cancer cell growth by altering the HPV-associated molecular pathways in cervical cancer cells [10]. Curcumin has been evaluated in several clinical studies for its action toward pre-cancer lesions and surrogate tumor biomarkers. For example, patients with advanced colorectal cancer consuming $3.6 \mathrm{~g}$ curcumin per day for 4 months evidenced in leukocytes, a reduction in inducible prostaglandin E2 levels, an indicator of cyclooxygenase (COX)2 activity. Likewise, levels of the deoxyguanosine M1G adduct, an indicator of oxidative DNA damage, were decreased in malignant colorectal tissue of individuals consuming $3.6 \mathrm{~g}$ curcumin for 1 week. In a small pilot study, curcumin (1440 mg/day along with $60 \mathrm{mg}$ Quercetin) lowered the number and size of polyps in patients with familial adenomatous polyposis. The mechanisms underlying curcumin's anti-cancer actions include inhibiting carcinogen metabolism; suppressing tumor invasion and metastasis; disrupting regulation of transcription factors, growth factors, protein kinases, or mTOR; and modulating levels of inflammatory cytokines that control cell proliferation, angiogenesis, and apoptosis.

Curcumin has been shown to cross the blood-brain barrier and lead to various improvements in the pathological process of Alzheimer's disease $(5,6,7)$. Alzheimer's disease is a neurodegenerative disease characterized by progressive cognitive deterioration together with declining activities of daily living and behavioral changes [10]. According to James A. Duke, more than 50 studies on turmeric's effects indicate that extracts of turmeric contain a number of natural agents that block the formation of $\mathrm{B}$-amyloid, the substance responsible for the plaques that slowly obstruct cerebral function, aggregation and fibril formation as well as to stimulate B-amyloid removal by mononuclear cell, delayed degradation of neurons, metal-chelation, anti-inflammatory, and antioxidant property, improve overall memory [6]. One recent study, published in the journal Stem Cell Research \& Therapy, linked turmeric extract to the growth of stem cells in the brains of live rats, potentially paving the way for new treatments of degenerative brain diseases such as Alzheimer's disease in humans. Curcumin in turmeric has a potential role in the prevention and treatment of Alzheimer's disease, according to a study published in the Annals of Indian Academy of Neurology. For example, in an in vivo study, curcumin injected into the blood ( $7.5 \mathrm{mg} / \mathrm{kg}$ per day for 1 week) disrupted existing amyloid plaques and partially reversed neurite distortions [11].

There are several different types of arthritis characterized by some sort of inflammation in the joints [3,7]. Given that curcumin is a potent anti-inflammatory, it makes sense that it could help with arthritis [3,5]. A 2010 clinical trial found that a turmeric supplement, Meriva (standardized to $75 \%$ curcumin combined with phosphatidylcholine) provided long-term improvement in pain and function in 100 patients with knee osteoarthritis (OA) [13]. Later, in 2012, a small pilot study of patients with rheumatoid arthritis (RA), a curcumin product, BCM-95 reduced joint pain and swelling and was even more effective than an anti-inflammatory drug [13]. Administration of curcumin to rodents (eg, $4 \mathrm{mg} / \mathrm{kg}$ per day, intraperitoneally) using experimental models of arthritis resulted in reduced levels of tissue inflammation as well as decreased expression of inflammationassociated cytokines and other inflammatory mediators [11]. Notably, curcumin can decrease expression of COX-2 and, in combination with celecoxib, can synergistically inhibit the COX-2 activity and cell proliferation associated with OA [11]. Other natural products, such as the isothiocyanate sulforaphane, may synergize with curcumin in suppressing inflammation $[6,11]$.

New research also suggests that turmeric may play a vital role in fighting HIV/AIDS, particularly HIV-type 1 [1]. In a recent study at the Jawaharlal Nehru Centre for Advanced Scientific Research in Bangalore, India, when scientists gave curcumin to HIV-infected cells in the laboratory, the virus stopped replicating [1]. Several studies have shown that people who have HIV/AIDS are deficient in many antioxidant vitamins and minerals, and it is believed that it is the powerful anti-oxidant properties of turmeric that combat the disease [1]. "Curcumin's anti-oxidant properties protect DNA from the ravages of the virus. It is also anti-microbial, so it will help prevent the many opportunistic illnesses associated with HIV/AIDS", says Dr. Susan Kowalsky, N.D., a naturopathic doctor in Norwich, Vermont [1]. In a study at Harvard Medical School, research showed that curcumin prevented the reproduction of HIV by blocking a specific gene that activates the virus and causes it to spread [1]. Another study showed that it may help decrease the reproduction of HIV [1].

Turmeric has proved to be beneficial in combating countless diseases and benefits for longevity is certainly one of them. For this reason, curcumin has become very popular as an anti-aging supplement. But given that oxidation and inflammation are believed to play a role in ageing, curcumin may have effects that go way beyond just prevention of disease [7]. 
Turmeric has been proven effective in treating some of the most intense ailments including multiple sclerosis, atherosclerosis, Sexually Transmitted Diseases (Hepatitis, Genital Herpes), irritable bowel syndrome, (IBS), a type of inflammatory bowel disease called Crohn's disease, gum disease (gingivitis), heartburn (dyspepsia), stomach pain, intestinal gas, stomach bloating, kidney inflammation (Lupus nephritis), stomach ulcers (peptic ulcer disease and Helicobacter pylori or H-pylori), external ulcers, itchy skin (pruritus), tuberculosis, a type of inflammatory bowel disease called ulcerative colitis, fibromyalgia, menstrual problems, the risk of childhood leukemia, lung infections, indigestion, water retention, worms, eczema, eye infections, internal mouth soreness, chicken pox, shingles, allergy, scabies, loss of appetite, jaundice, acne, urinary tract infections, kidney infections, gallstones, gallbladder disorders, anemia, hemorrhoids, liver disease, leprosy, amenorrhea, edema, bronchitis, common cold, headaches, conjunctivitis, bursitis, food poisoning, parasites, fever, diarrhea, poor circulation, lower back and abdominal pain. It can also be used as a mosquito repellent and wound healer for pain, sprain, ringworms, bruising, leech bites and immediate cure for scorpion stings. Turmeric also helps balance the female reproductive system, lactation systems, and purifies the uterus and breast milk, and in men it purifies and improves the health of semen, which is counterintuitive for a pungent bitter [1,3,5,7,8,10,11,12,14-17].

In addition to all the other benefits mentioned above, when consumed Turmeric (water, Turmeric Tea, Golden Milk, juice) every

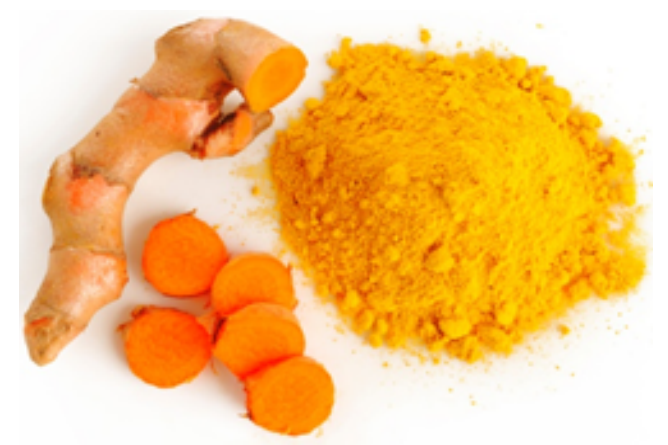

Figure 2: Forms of turmeric.

\begin{tabular}{|c|c|c|}
\hline \multicolumn{3}{|c|}{$\begin{array}{l}\text { Turmeric, ground } \\
\text { (Note: "--" indicates data unavailable) }\end{array}$} \\
\hline $\begin{array}{l}2.00 \mathrm{tsp} \\
(4.40 \mathrm{~g})\end{array}$ & \multicolumn{2}{|c|}{ Gl: very low } \\
\hline \multicolumn{3}{|c|}{ BASIC MACRONUTRIENTS AND CALORIES } \\
\hline Nutrient & Amount & $\begin{array}{l}\text { DRI/DV } \\
(\%)\end{array}$ \\
\hline Protein & $0.34 \mathrm{~g}$ & 1 \\
\hline Carbohydrates & $2.86 \mathrm{~g}$ & 1 \\
\hline Fat - total & $0.43 \mathrm{~g}$ & -- \\
\hline Dietary Fiber & $0.93 \mathrm{~g}$ & 4 \\
\hline Calories & 15.58 & 1 \\
\hline \multicolumn{3}{|c|}{ MACRONUTRIENT AND CALORIE DETAIL } \\
\hline \multicolumn{3}{|c|}{ Carbohydrate } \\
\hline Starch & $--g$ & \\
\hline Total Sugars & $0.14 \mathrm{~g}$ & \\
\hline Monosaccharides & $0.04 \mathrm{~g}$ & \\
\hline Fructose & $0.02 \mathrm{~g}$ & \\
\hline Glucose & $0.02 \mathrm{~g}$ & \\
\hline
\end{tabular}

\begin{tabular}{|c|c|c|}
\hline Galactose & $0.00 \mathrm{~g}$ & \\
\hline Disaccharides & $0.10 \mathrm{~g}$ & \\
\hline Lactose & $0.00 \mathrm{~g}$ & \\
\hline Maltose & $0.00 \mathrm{~g}$ & \\
\hline Sucrose & $0.10 \mathrm{~g}$ & \\
\hline Soluble Fiber & $--g$ & \\
\hline Insoluble Fiber & $-\mathrm{g}$ & \\
\hline Other Carbohydrates & $1.79 \mathrm{~g}$ & \\
\hline \multicolumn{3}{|l|}{ Fat } \\
\hline Monounsaturated Fat & $0.07 \mathrm{~g}$ & \\
\hline Polyunsaturated Fat & $0.10 \mathrm{~g}$ & \\
\hline Saturated Fat & $0.14 \mathrm{~g}$ & \\
\hline Trans Fat & $0.00 \mathrm{~g}$ & \\
\hline Calories from Fat & 3.91 & \\
\hline Calories from Saturated Fat & 1.24 & \\
\hline Calories from Trans Fat & 0.00 & \\
\hline Cholesterol & $0.00 \mathrm{mg}$ & \\
\hline Water & $0.50 \mathrm{~g}$ & \\
\hline \multicolumn{3}{|l|}{ MICRONUTRIENTS } \\
\hline \multicolumn{3}{|l|}{ Vitamins } \\
\hline \multicolumn{3}{|l|}{ Water-Soluble Vitamins } \\
\hline \multicolumn{3}{|l|}{ B-Complex Vitamins } \\
\hline Vitamin B1 & $0.01 \mathrm{mg}$ & 1 \\
\hline Vitamin B2 & $0.01 \mathrm{mg}$ & 1 \\
\hline Vitamin B3 & $0.23 \mathrm{mg}$ & 1 \\
\hline Vitamin B3 (Niacin Equivalents) & $0.23 \mathrm{mg}$ & \\
\hline Vitamin B6 & $0.08 \mathrm{mg}$ & 5 \\
\hline Vitamin B12 & $0.00 \mathrm{mcg}$ & 0 \\
\hline Biotin & -- mcg & -- \\
\hline Choline & $2.16 \mathrm{mg}$ & 1 \\
\hline Folate & $1.72 \mathrm{mcg}$ & 0 \\
\hline Folate (DFE) & $1.72 \mathrm{mcg}$ & \\
\hline Folate (food) & $1.72 \mathrm{mcg}$ & \\
\hline Pantothenic Acid & $--\mathrm{mg}$ & -- \\
\hline Vitamin C & $1.14 \mathrm{mg}$ & 2 \\
\hline \multicolumn{3}{|l|}{ Fat-Soluble Vitamins } \\
\hline \multicolumn{3}{|l|}{ Vitamin A (Retinoids and Carotenoids) } \\
\hline Vitamin A International Units (IU) & $0.00 \mathrm{IU}$ & \\
\hline Vitamin A mcg Retinol Activity Equivalents (RAE) & $0.00 \mathrm{mcg}$ (RAE) & 0 \\
\hline Vitamin A mcg Retinol Equivalents (RE) & $0.00 \mathrm{mcg}(\mathrm{RE})$ & \\
\hline Retinol mcg Retinol Equivalents (RE) & $0.00 \mathrm{mcg}(\mathrm{RE})$ & \\
\hline Carotenoid mcg Retinol Equivalents (RE) & $0.00 \mathrm{mcg}(\mathrm{RE})$ & \\
\hline Alpha-Carotene & $0.00 \mathrm{mcg}$ & \\
\hline Beta-Carotene & $0.00 \mathrm{mcg}$ & \\
\hline Beta-Carotene Equivalents & $0.00 \mathrm{mcg}$ & \\
\hline Cryptoxanthin & $0.00 \mathrm{mcg}$ & \\
\hline Lutein and Zeaxanthin & $0.00 \mathrm{mcg}$ & \\
\hline Lycopene & $0.00 \mathrm{mcg}$ & \\
\hline \multicolumn{3}{|l|}{ Vitamin D } \\
\hline Vitamin D International Units (IU) & $0.00 \mathrm{IU}$ & 0 \\
\hline Vitamin D mcg & $0.00 \mathrm{mcg}$ & \\
\hline \multicolumn{3}{|l|}{ Vitamin E } \\
\hline Vitamin E mg Alpha-Tocopherol Equivalents (ATE) & $0.14 \mathrm{mg}$ (ATE) & 1 \\
\hline Vitamin E International Units (IU) & $0.20 \mathrm{IU}$ & \\
\hline Vitamin E mg & $0.14 \mathrm{mg}$ & \\
\hline Vitamin K & $0.59 \mathrm{mcg}$ & 1 \\
\hline \multicolumn{3}{|l|}{ Minerals } \\
\hline Boron & -- mcg & \\
\hline Calcium & $8.05 \mathrm{mg}$ & 1 \\
\hline Chloride & -- mg & \\
\hline Chromium & $--\mathrm{mcg}$ & -- \\
\hline
\end{tabular}




\begin{tabular}{|c|c|c|}
\hline Copper & $0.03 \mathrm{mg}$ & 3 \\
\hline Fluoride & -- mg & -- \\
\hline lodine & $--\mathrm{mcg}$ & -- \\
\hline Iron & $1.82 \mathrm{mg}$ & 10 \\
\hline Magnesium & $8.49 \mathrm{mg}$ & 2 \\
\hline Manganese & $0.34 \mathrm{mg}$ & 17 \\
\hline Molybdenum & -- mcg & -- \\
\hline Phosphorus & $11.79 \mathrm{mg}$ & 2 \\
\hline Potassium & $111.10 \mathrm{mg}$ & 3 \\
\hline Selenium & $0.20 \mathrm{mcg}$ & 0 \\
\hline Sodium & $1.67 \mathrm{mg}$ & 0 \\
\hline Zinc & $0.19 \mathrm{mg}$ & 2 \\
\hline \multicolumn{3}{|l|}{ INDIVIDUAL FATTY ACIDS } \\
\hline Omega-3 Fatty Acids & $0.02 \mathrm{~g}$ & 1 \\
\hline Omega-6 Fatty Acids & $0.07 \mathrm{~g}$ & \\
\hline \multicolumn{3}{|l|}{ Monounsaturated Fats } \\
\hline 14:1 Myristoleic & $0.00 \mathrm{~g}$ & \\
\hline 15:1 Pentadecenoic & $0.00 \mathrm{~g}$ & \\
\hline 16:1 Palmitol & $0.00 \mathrm{~g}$ & \\
\hline 17:1 Heptadecenoic & $0.00 \mathrm{~g}$ & \\
\hline 18:1 Oleic & $0.07 \mathrm{~g}$ & \\
\hline 20:1 Eicosenoic & $0.00 \mathrm{~g}$ & \\
\hline 22:1 Erucic & $0.00 \mathrm{~g}$ & \\
\hline 24:1 Nervonic & $0.00 \mathrm{~g}$ & \\
\hline \multicolumn{3}{|l|}{ Polyunsaturated Fatty Acids } \\
\hline 18:2 Linoleic & $0.07 \mathrm{~g}$ & \\
\hline 18:2 Conjugated Linoleic (CLA) & $-\mathrm{g}$ & \\
\hline 18:3 Linolenic & $0.02 \mathrm{~g}$ & \\
\hline 18:4 Stearidonic & $--g$ & \\
\hline 20:3 Eicosatrienoic & $-\mathrm{g}$ & \\
\hline 20:4 Arachidonic & $--g$ & \\
\hline 20:5 Eicosapentaenoic (EPA) & $-\mathrm{g}$ & \\
\hline 22:5 Docosapentaenoic (DPA) & $--g$ & \\
\hline 22:6 Docosahexaenoic (DHA) & $-\mathrm{g}$ & \\
\hline \multicolumn{3}{|l|}{ Saturated Fatty Acids } \\
\hline 4:0 Butyric & $0.00 \mathrm{~g}$ & \\
\hline 6:0 Caproic & $0.00 \mathrm{~g}$ & \\
\hline 8:0 Caprylic & $0.00 \mathrm{~g}$ & \\
\hline 10:0 Capric & $0.01 \mathrm{~g}$ & \\
\hline 12:0 Lauric & $0.02 \mathrm{~g}$ & \\
\hline 14:0 Myristic & $0.01 \mathrm{~g}$ & \\
\hline 15:0 Pentadecanoic & $0.00 \mathrm{~g}$ & \\
\hline 16:0 Palmitic & $0.07 \mathrm{~g}$ & \\
\hline 17:0 Margaric & $0.00 \mathrm{~g}$ & \\
\hline 18:0 Stearic & $0.01 \mathrm{~g}$ & \\
\hline 20:0 Arachidic & $0.00 \mathrm{~g}$ & \\
\hline 22:0 Behenate & $0.00 \mathrm{~g}$ & \\
\hline 24:0 Lignoceric & $0.00 \mathrm{~g}$ & \\
\hline \multicolumn{3}{|l|}{ INDIVIDUAL AMINO ACIDS } \\
\hline Alanine & $-\mathrm{g}$ & \\
\hline Arginine & $-\mathrm{g}$ & \\
\hline Aspartic Acid & $-\mathrm{g}$ & \\
\hline Cysteine & $-\mathrm{g}$ & \\
\hline Glutamic Acid & $--g$ & \\
\hline Glycine & $-\mathrm{g}$ & \\
\hline Histidine & $-\mathrm{g}$ & \\
\hline Isoleucine & $--g$ & \\
\hline Leucine & $--g$ & \\
\hline Lysine & $-g$ & \\
\hline Methionine & $--g$ & \\
\hline Phenylalanine & $--g$ & \\
\hline
\end{tabular}

\begin{tabular}{|l|c|c|}
\hline Proline & $-\mathrm{g}$ & \\
\hline Serine & $-\mathrm{g}$ & $-\mathrm{g}$ \\
\hline Threonine & $-\mathrm{g}$ & \\
\hline Tryptophan & $-\mathrm{g}$ & \\
\hline Tyrosine & $--\mathrm{g}$ & \\
\hline Valine & & \\
\hline OTHER COMPONENTS & $0.26 \mathrm{~g}$ & \\
\hline Ash & $--\mathrm{g}$ & \\
\hline Organic Acids (Total) & $--\mathrm{g}$ & \\
\hline Acetic Acid & $--\mathrm{g}$ & \\
\hline Citric Acid & $--\mathrm{g}$ & \\
\hline Lactic Acid & $-\mathrm{g}$ & \\
\hline Malic Acid & $-\mathrm{g}$ & \\
\hline Taurine & $-\mathrm{g}$ & \\
\hline Sugar Alcohols (Total) & $--\mathrm{g}$ & \\
\hline Glycerol & $--\mathrm{g}$ & \\
\hline Inositol & $--\mathrm{g}$ & \\
\hline Mannitol & $--\mathrm{g}$ & \\
\hline Sorbitol & $--\mathrm{g}$ & \\
\hline Xylitol & $--\mathrm{mg}$ & \\
\hline Artificial Sweeteners (Total) & $--\mathrm{mg}$ & \\
\hline Aspartame & $--\mathrm{mg}$ & \\
\hline Saccharin & $0.00 \mathrm{~g}$ & \\
\hline Alcohol & $0.00 \mathrm{mg}$ & \\
\hline Caffeine & & \\
\hline Note: The nutient pofles provided & & \\
\hline
\end{tabular}

Note: The nutrient profiles provided in this chart are derived from The Food Processor, Version 10.12.0, ESHA Research, Salem, Oregon, USA. Among the $50,000+$ food items in the master database and 163 nutritional components per item, specific nutrient values were frequently missing from any particular food item. We chose the designation "--" to represent those nutrients for which no value was included in this version of the database.

Table 1: In-depth nutrient profile.

day, it detoxifies and cleanses blood and other bodily organs. When consuming Turmeric, be mindful that black pepper and healthy fat such as coconut/olive oil, almonds should always be included to get proper absorption of the nutrient piperine and avoid exposure of the curcumin to harsh stomach acids on its way to small intestines $[7,16]$ (Figure 2).

Turmeric can obviously stand the test of time. In the words of David Frawley "If I had only a single herb to depend upon for all possible health and dietary needs, I would without much hesitation choose the Indian spice turmeric" [1] (Table 1).

\section{References}

1. CFR - Code of Federal Regulations Title 21. FDA: U.S. Food and Drug Administration.

2. Turmeric (2015) Medline Plus: Trusted Health Information For You.

3. Gunnars K (2000) 10 Proven Health Benefits of Turmeric and Curcumin.

4. Turmeric (2015) The World's Healthiest Foods.

5. Turmeric (2013) University of Maryland Medical Center.

6. Weil A (2015) Three Reasons To Eat Turmeric. Cooking \& Recipes.

7. Turmeric.

8. Turmeric. Arthritis Foundation.

9. Turmeric Root Powder. Mountain Rose Herbs.

10. Turmeric: 5 (2015) Things You Didn't Know About The Superfood.

11. Turmeric Powder - Health Benefits, Uses \& Side Effects. Medindia: Network For Health.

12. Turmeric. Natural Society. 
13. Synopsis of Turmeric's Healing Properties. Turmeric: The Golden Spice of Life. 14. Turmeric Tonic.

15. Turmeric (Curcuma Longa).

16. Turmeric Herb Profile. Wellness Mama.

17. Turmeric Nutrition Facts. Power Your Diet.
18. MSI Funded Paper: Potential Health Benefits of Turmeric. (2010) McCormick Science Institute: Spice For Health.

19. Turmeric: The Golden Goddess (by Lisa Gallant C.A.S. A World Leader In Ayurvedic Education.

20. Turmeric. MindBodyGreen. 